\title{
Inhibitory effects of fermented extract of Ophiopogon japonicas on thrombin-induced vascular smooth muscle cells
}

\author{
JUN-HUI SONG ${ }^{1}$, GI HEE JEONG ${ }^{1}$, SUNG LYEA PARK ${ }^{1}$, SE YEON WON ${ }^{1}$, \\ NAM SOO PAEK ${ }^{2}$, BOG-HIEU LEE ${ }^{1}$ and SUNG-KWON MOON ${ }^{1}$ \\ ${ }^{1}$ Department of Food and Nutrition, Chung-Ang University, Anseong-si, Gyeonggi-do 456-756; \\ ${ }^{2}$ Mediogen, Jecheon-si, Chungcheongbuk-do 390-250, Republic of Korea
}

Received December 15, 2014; Accepted September 3, 2015

DOI: $10.3892 / \mathrm{mmr} .2015 .4499$

\begin{abstract}
Ophiopogon japonicus is known to have various pharmacological effects. The present study investigated the effects of an extract of fermented Ophiopogon japonicas (FEOJ) on thrombin-treated vascular smooth muscle cells (VSMCs). FEOJ treatment inhibited the proliferation of VSMCs treated with thrombin as indicated by an MTT assay. These inhibitory effects were associated with decreased phosphorylation of AKT, reduced expression of cyclin D1 and increased expression of p27KIP1 in thrombin-induced VSMCs. In addition, FEOJ treatment suppressed the thrombin-stimulated migration of VSMCs as demonstrated by a wound-healing migration assay. Furthermore, zymographic analyses demonstrated that treatment of FEOJ with VSMCs suppressed the thrombin-induced expression of matrix metalloproteinase (MMP)-2, which was attributed to the reduction of nuclear factor (NF) $-\kappa \mathrm{B}$ binding activity. Collectively, these results demonstrated that FEOJ induced p27KIP1 expression, reduced cyclin D1 expression and AKT phosphorylation, and inhibited MMP-2 expression mediated by downregulation of NF- $\kappa \mathrm{B}$ binding activity in thrombin-treated VSMCs, which led to growth inhibition and repression of migration. These results supported the use of FEOJ for the prevention of vascular diseases and provided novel insight into the underlying mechanism of action.
\end{abstract}

Correspondence to: Professor Bog-Hieu Lee or Professor Sung-Kwon Moon, Department of Food and Nutrition, Chung-Ang University, 4726 Seodong-daero, Daedeok-myeon, Anseong-si, Gyeonggi-do 456-756, Republic of Korea

E-mail: lbheelb@cau.ac.kr

E-mail: sumoon66@dreamwiz.com

Key words: a fermented extract of Ophiopogon japonicas, vascular smooth muscle cells, thrombin, proliferation, AKT, p27KIP1, migration

\section{Introduction}

Thrombin is one of the key components for the coagulation cascade and homeostasis $(1,2)$. It also has a role in the proliferation and migration of vascular smooth muscle cells (VSMCs), which contributes to atherosclerosis and re-stenosis $(1,2)$. The proliferation of VSMCs induced by thrombin is associated with the phosphorylation of signaling molecules, including extracellular signal-regulated kinase 1/2 (ERK1/2), c-Jun N-terminal kinase (JNK), p38/mitogen-activated protein kinase (MAPK) and AKT (2), leading to the activation of their respective pathways. After stimulation with thrombin, VSMCs undergo G1-to-S-phase cell-cycle transition, which is tightly regulated by cyclin D1 and p27KIP1 $(2,3)$. In addition, matrix metalloproteinase-2 (MMP-2) degrades type IV collagen, leading to VSMC migration and the progression of arterial lesions $(4,5)$. A previous study has demonstrated that thrombin stimulates the MMP-2 expression via transcription factor nuclear factor (NF)- $\mathrm{kB}$ in chondrosarcoma cells (6).

Ophiopogon japonicas (OJ), a plant distributed in southeast Asia, has been used as a Traditional Chinese Medicine (7). Numerous studies have indicated the pharmaceutical effects of OJ, including anti-inflammatory, anti-cardiovascular and anti-thrombotic activities (7-11). Several chemical constituents of OJ, including ruscogenin and ophiopogonin $\mathrm{D}$, have been identified (8). Microbial fermentation of plants has beneficial effects, including the enrichment of desirable metabolites generated by the beneficial probiotic bacteria $(12,13)$. The present study reported on the inhibitory effects of a fermented extract of OJ (FEOJ) on the proliferation and migration of thrombin-treated VSMCs.

\section{Materials and methods}

Materials. Polyclonal antibodies against cyclin E (sc-481), CDK2 (sc-163), CDK4 (sc-260), p21WAF1 (sc-756), p53 (sc-126), p27 (sc-528) and GAPDH (sc-20357) were obtained from Santa Cruz Biotechnology Inc. (Santa Cruz, CA, USA). Monoclonal antibodies against cyclin D1 (04-221) were obtained from Millipore (Millipore, Temecula, CA, USA). Polyclonal antibodies against ERK (9102), phospho-ERK (9101), p38 MAP kinase (9212), phospho-p38 MAP kinase (9211), JNK (9258), phospho-JNK (9251), AKT (9272) and 
phospho-AKT (9271) were obtained from Cell Signaling Technology Inc. (Danvers, MA, USA). Goat anti-rabbit IgG-horseradish peroxidase (HRP) (sc-2004), goat anti-mouse IgG-HRP (sc-2005) and donkey anti-goat IgG-HRP (sc-2020) were purchased from Santa Cruz Biotechnology Inc. Western Lightning Plus-ECL was obtained from PerkinElmer, Inc. (PerkinElmer, MA, USA). A Nuclear Extract kit and EMSA Gel Shift kit were obtained from Panomics (Fremont, CA, USA).

Preparation of FEOJ. The roots of OJ (Milyang, Korea), harvested in April 2012, were used for the preparation of an aqueous extract. In brief, dried OJ $(3.5 \mathrm{~kg})$ was extracted with $\sim 6,500 \mathrm{ml}$ water at $105^{\circ} \mathrm{C}$ for $60 \mathrm{~min}$. The aqueous filtrates of $\mathrm{OJ}$ were adjusted to $\mathrm{pH} 6.5$ with $\mathrm{NaOH}$ (Youngjin Chemistry, Bucheon, Korea), and autoclaved (JS Research, Gongju, Korea) for $20 \mathrm{~min}$ at $121^{\circ} \mathrm{C}$. Subsequently, Cordyceps militaris was inoculated and fermented by shaking at $141 \mathrm{x} \mathrm{g}$ at $25^{\circ} \mathrm{C}$ for 10 days. For the second fermentation was conducted with a combination of 3 types of lactic acid bacteria (Lactobacillus plantarum, Enterococcus faecium and Bifidobacterium longum obtained from Mediogen Co., Ltd., Seoul, Korea), the culture medium was adjusted to $\mathrm{pH} 6.5$ with $\mathrm{NaOH}$, sterilized for $40 \mathrm{~min}$ at $80^{\circ} \mathrm{C}$ and then cooled. The concoction was inoculated with one percent of lactic acid bacteria and fermented for two days at $37^{\circ} \mathrm{C}$. The concoction was inoculated with $1 \%$ of each lactic acid bacteria and fermented for 2 days at $37^{\circ} \mathrm{C}$. The supernatant was filtered, heated at $80^{\circ} \mathrm{C}$ for $40 \mathrm{~min}$ and freeze-dried. Aqueous extracts were used in the subsequent experiments.

Cell culture. Enzymatic digestion was used to isolate the rat aortic smooth muscle cells (VSMCs) as previously reported (3). Briefly, the aortas from two young male Sprague-Dawley rats (age, 8 weeks; weight, 200-250 g; DHbiolink, Seoul, Korea) were excised. After elimination of the adventitia and endothelium, the aortas were sliced, minced and placed in $5 \mathrm{ml}$ digestion solution (containing $0.125 \mathrm{mg} / \mathrm{ml}$ elastase, $0.25 \mathrm{mg} / \mathrm{ml}$ soybean trypsin inhibitor, $10 \mathrm{mg} / \mathrm{ml}$ collagenase $\mathrm{I}, 2.0 \mathrm{mg} / \mathrm{ml}$ crystallized bovine albumin, and $15 \mathrm{mM}$ HEPES; all from Sigma-Aldrich; St Louis, MO, USA) at $37^{\circ} \mathrm{C}$. After digestion for $45 \mathrm{~min}$, the cellular digests were filtered using a sterile 100- $\mu \mathrm{M}$ nylon membrane (BD Biosciences, Franklin Lakes, NJ, USA), centrifuged at $157 \mathrm{x}$ g for $10 \mathrm{~min}$, and maintained in Dulbecco's modified Eagle's medium (DMEM; Corning, Corning, NY, USA) supplemented with $10 \%$ fetal bovine serum (FBS; Corning). The characterization of VSMCs was confirmed by immunofluorescence staining with a monoclonal antibody against SM- $\alpha$-actin (cat. no. A7067; Sigma-Aldrich) using a fluorescent microscope (Olympus BX61; Olympus Corporation, Seoul, Korea). Isolated cells were maintained in DMEM containing 10\% FBS, 2 mM glutamine (Sigma-Aldrich), $50 \mu \mathrm{g} / \mathrm{ml}$ gentamycin (Sigma-Aldrich), and $50 \mu \mathrm{l} / \mathrm{ml}$ amphotericin-B (Sigma-Aldrich) at $37^{\circ} \mathrm{C}$ in a humidified $5 \% \mathrm{CO}_{2}$ atmosphere. All experiments were accomplished with cells at passages five to eight. VSMCs at $80 \%$ confluence were synchronized by incubation for $24 \mathrm{~h}$ in DMEM without FBS. The study was approved by the ethics committee of Chung-Ang University (Seoul, Korea).
Cell viability assay. Growth-arrested VSMCs $\left(2.0 \times 10^{5}\right.$ cells per well) in 24-well plates were pre-treated with FEOJ $(0,1,5$ and $25 \mu \mathrm{g} / \mathrm{ml}$ for $40 \mathrm{~min}$ ), followed by incubation with thrombin (2 U/ml; Sigma-Aldrich) for various time periods $(6,12$ and $24 \mathrm{~h})$. Cell viability was determined using a modification of the 3-(4,5-dimethylthiazol-2-yl)-2,5-diphenyltetrazolium bromide (MTT; Sigma-Aldrich), which was based on the conversion of tetrazolium salt MTT to the formazan product by mitochondrial dehydrogenase (3). The formazan product was dissolved in dimethyl sulfoxide (Sigma-Aldrich). Dissolved formazan was read on a multi-well scanning spectrophotometer (Sclavo, Siena, Italy) by measuring absorbance at $570 \mathrm{~nm}$.

Immunoblot analysis. The VSMCs ( $8 \times 10^{6}$ cells/well), grown to near confluence in $100-\mathrm{mm}$ tissue culture plates, were synchronized and pre-treated with FEOJ $(0,1,5$ and $25 \mu \mathrm{g} / \mathrm{ml}$ for $40 \mathrm{~min}$. Subsequently, cells were incubated with thrombin ( $2 \mathrm{U} / \mathrm{ml}$ ) for various durations $\left(6,12\right.$ and $24 \mathrm{~h}$ ) at $37^{\circ} \mathrm{C}$. The cells were then washed twice with cold phosphate-buffered saline and freeze-thawed in $250 \mu 1$ lysis buffer $(50 \mathrm{mM}$ HEPES [pH 7.5], $150 \mathrm{mM} \mathrm{NaCl,} 1 \mathrm{mM}$ EDTA, $2.5 \mathrm{mM}$ ethylene glycol tetraacetic acid, $1 \mathrm{mM}$ dithiothreitol, $10 \mathrm{mM}$ $\beta$-glycerophosphate, $1 \mathrm{mM} \mathrm{NaF}, 0.1 \mathrm{mM} \mathrm{Na} \mathrm{VO}_{4}, 0.1 \mathrm{mM}$ phenylmethylsulfonyl fluoride, $10 \%$ glycerol, $0.1 \%$ Tween-20, $10 \mathrm{~g} / \mathrm{ml}$ leupeptin and $2 \mu \mathrm{g} / \mathrm{ml}$ aprotinin; Sigma-Aldrich). The cells were then scraped into $1.5-\mathrm{ml}$ tubes. The lysates were placed on ice for $15 \mathrm{~min}$ and then centrifuged at $16,128 \mathrm{x} \mathrm{g}$ for $20 \mathrm{~min}$ at $4^{\circ} \mathrm{C}$. The protein concentration of the supernatant was determined using a Bradford reagent method (Bio-Rad Laboratories, Inc., Richmond, CA, USA). Equal amounts of cellular proteins $(30 \mu \mathrm{g})$ were resolved by electrophoresis on a $0.1 \%$ SDS $-10 \%$ polyacrylamide gel under denaturing conditions. The proteins were transferred electrophoretically to nitrocellulose membranes (Hybond, GE Healthcare, Little Chalfont, UK). After blocking with $10 \mathrm{mmol} / \mathrm{l}$ Tris- $\mathrm{HCl}(\mathrm{pH}$ 8.0), $150 \mathrm{mmol} / 1 \mathrm{NaCl}$ and $5 \%$ (wt/vol) non-fat dry milk (BD Biosciences) for $2 \mathrm{~h}$, the membranes were treated with 1:1,000 dilution of primary antibodies at $4^{\circ} \mathrm{C}$ for $12 \mathrm{~h}$, followed by incubation with 1:5,000 dilution of goat anti-rabbit IgG HRP, goat anti-mouse IgG HRP and donkey anti-goat IgG HRP secondary antibodies for $2 \mathrm{~h}$. The immunocomplexes were detected using the Western Lightning Plus-ECL(PerkinElmer, Inc.). The experiments were repeated at least three times for the immunoblotting studies $(3,14)$. Gray value analysis of the blots was measured by ImagePro Plus 6.0 software (Media Cybernetics, Rockville, MD, USA).

Wound-healing migration assay. The cells $\left(5.0 \times 10^{5}\right.$ cells per well) were pre-treated with FEOJ $(0,1,5$ and $25 \mu \mathrm{g} / \mathrm{ml})$ for $40 \mathrm{~min}$ and a line-shaped incision to the confluent monolayer of growth-arrested cells $\left(2.0 \times 10^{5}\right.$ cells per well $)$ was generated using a $2-\mathrm{mm}$ pipette tip. Cells were then treated with thrombin $(2 \mathrm{U} / \mathrm{ml})$ for $24 \mathrm{~h}$, allowing them to migrate into the scraped area. Images were captured using an inverted microscope (magnification, x40; Optika, Ponteranica, Italy).

Zymography. Growth arrested VSMCs $\left(2 \times 10^{5}\right.$ cells per well $)$ in 24-well plates were pre-treated with FEOJ $(0,1,5$ and $25 \mu \mathrm{g} / \mathrm{ml}$ for $40 \mathrm{~min}$ ), followed by incubation with thrombin ( $2 \mathrm{U} / \mathrm{ml}$, Sigma-Aldrich) for $24 \mathrm{~h}$. The conditioned medium 


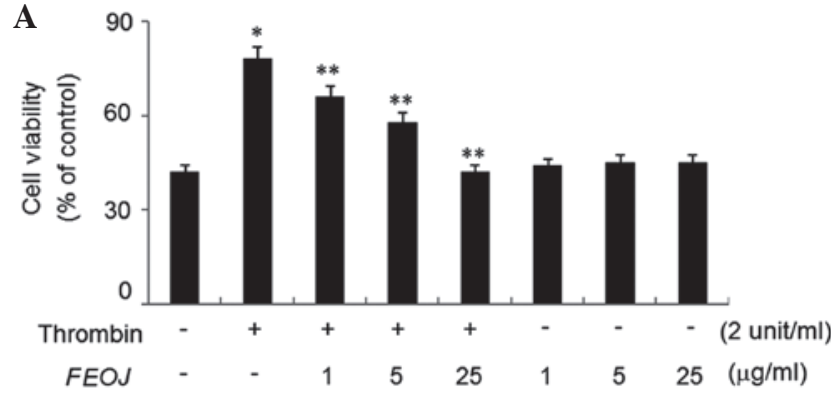

B

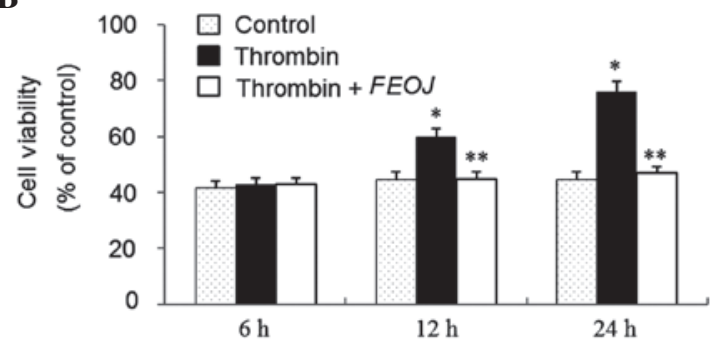

Figure 1. FEOJ inhibits the proliferation in thrombin-treated VSMCs. (A) After starvation for $24 \mathrm{~h}$, the cells were pre-treated with FEOJ at the indicated concentrations for $40 \mathrm{~min}$, followed by stimulation with or without thrombin ( 2 unit $/ \mathrm{ml}$ ) for $24 \mathrm{~h}$. (B) After $24 \mathrm{~h}$ of starvation, the cells were pre-treated with FEOJ $(25 \mu \mathrm{g} / \mathrm{ml})$ for $30 \mathrm{~min}$. The cells were stimulated with thrombin $(2 \mathrm{unit} / \mathrm{ml})$ in the presence or absence of FEOJ $(25 \mu \mathrm{g} / \mathrm{ml})$ for the indicated times. Cell viability was assessed using a modified MTT assay. Values are expressed as the mean \pm standard error from three experiments performed in triplicate. ${ }^{*} \mathrm{P}<0.01$ compared with no thrombin treatment. ${ }^{* * *} \mathrm{P}<0.01$ compared with no thrombin treatment. FEOJ, extract of fermented Ophiopogon japonicas.

was electrophoresed on a polyacrylamide gel containing $1 \mathrm{mg} / \mathrm{ml}$ gelatin (Sigma-Aldrich). The gel was then washed at room temperature for $2 \mathrm{~h}$ with $2.5 \%$ Triton $\mathrm{X}-100$ and maintained at $37^{\circ} \mathrm{C}$ overnight in a buffer containing $10 \mathrm{mM}$ $\mathrm{CaCl}_{2}, 150 \mathrm{mM} \mathrm{NaCl}$, and $50 \mathrm{mM}$ Tris- $\mathrm{HCl}$, $\mathrm{pH} 7.5$ (all from Sigma-Aldrich). The gel was stained with $0.2 \%$ Coomassie blue (Bio-Rad, Laboratories, Inc.) and images were captured using a light box (Matin International, Co., Ltd., Seoul, Korea). Proteolysis was detected as a white zone in a dark blue field by ImagePro Plus 6.0 software (Media Cybernetics).

Preparation of nuclear extracts and electrophoretic mobility shift assay (EMSA). VSMCs $\left(8 \times 10^{6}\right.$ cells/well), grown to $\sim 80 \%$ confluence in $100 \mathrm{~mm}$ tissue culture plates, were synchronized and pre-treated with EFOJ $(0,1,5$ and $25 \mu \mathrm{g} / \mathrm{ml})$ for $40 \mathrm{~min}$. Subsequently, cells were incubated with thrombin $(2 \mathrm{U} / \mathrm{ml})$ for $24 \mathrm{~h}$ at $37^{\circ} \mathrm{C}$. An EMSA was performed to determine the nuclear factor (NF) $-\kappa B$ DNA binding activity, in which a labeled double-stranded DNA sequence (NF- $\kappa$; CAGTGGAATTCC CCAGCC; Bioneer Corporation, Daejeon, Korea) was used as a DNA probe to bind active $\mathrm{NF}-\kappa \mathrm{B}$ protein in nuclear extracts. Nuclear extracts were prepared with a Nuclear Extract kit (Panomics, Fremont, CA, USA). The EMSA was accomplished by incubating a biotin-labeled transcription factor $(\mathrm{NF}-\kappa \mathrm{B})$ probe with treated and untreated nuclear extracts. The labeled oligonucleotides and nuclear extracts were incubated with or without a 100-fold molar excess of unlabeled NF- $\kappa$ B DNA sequence as a competitor. Samples were electrophoresed on a non-denaturing $6 \%$ polyacrylamide gel. The NF- $\mathrm{KB}-\mathrm{DNA}$
A

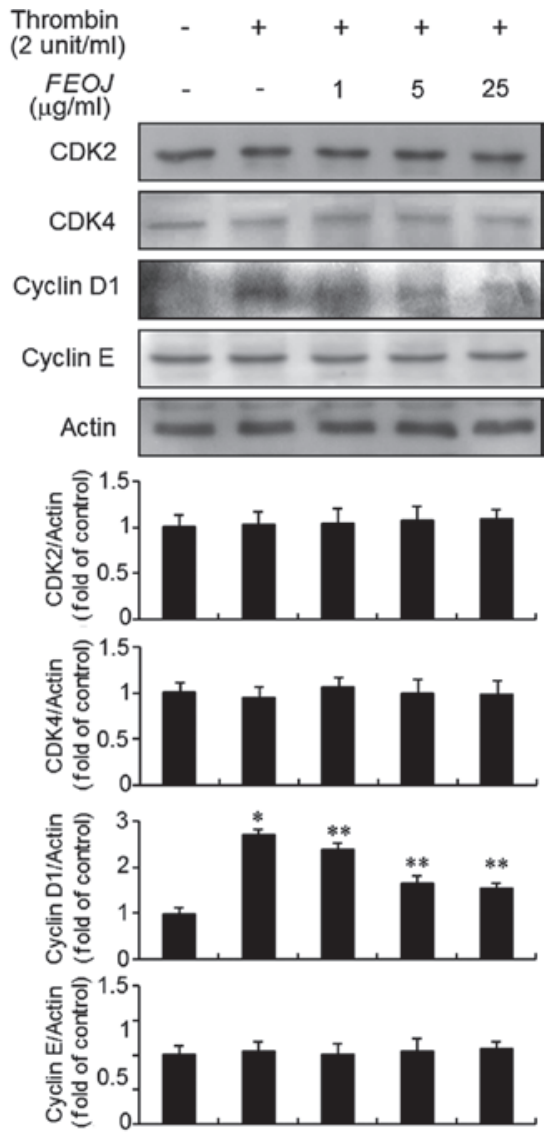

B

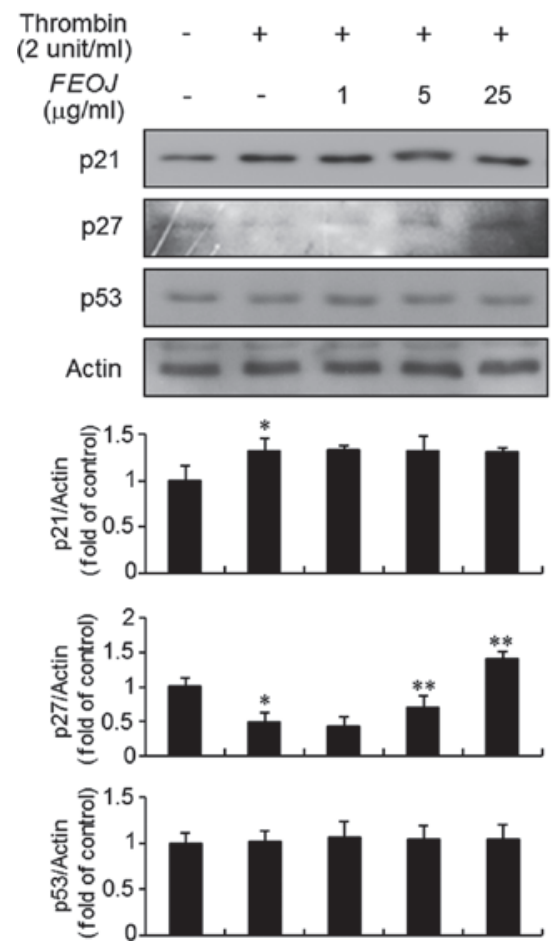

Figure 2. FEOJ inhibits the expression of cyclin D1 and induces the expression of p27KIP1 in thrombin-treated VSMCs. (A and B) VSMCs were stimulated with thrombin ( $2 \mathrm{unit} / \mathrm{ml})$ in the presence or absence of the indicated concentrations of FEOJ for $24 \mathrm{~h}$ and a immunoblot analysis was performed with antibodies specific for cyclin D1, cyclin E, CDK2, CDK4, p21WAF1, p27KIP1 and $\mathrm{p} 53$. Blots representative of three experiments are shown and protein levels were quantified by grey value analysis with normalization to GAPDH expression. Values are expressed as the mean \pm standard error from three independent experiments. ${ }^{*} \mathrm{P}<0.01$ compared with no thrombin treatment. ${ }^{* *} \mathrm{P}<0.01$ compared with no thrombin treatment. FEOJ, extract of fermented Ophiopogon japonicas; VSMC, vascular smooth muscle cell. 

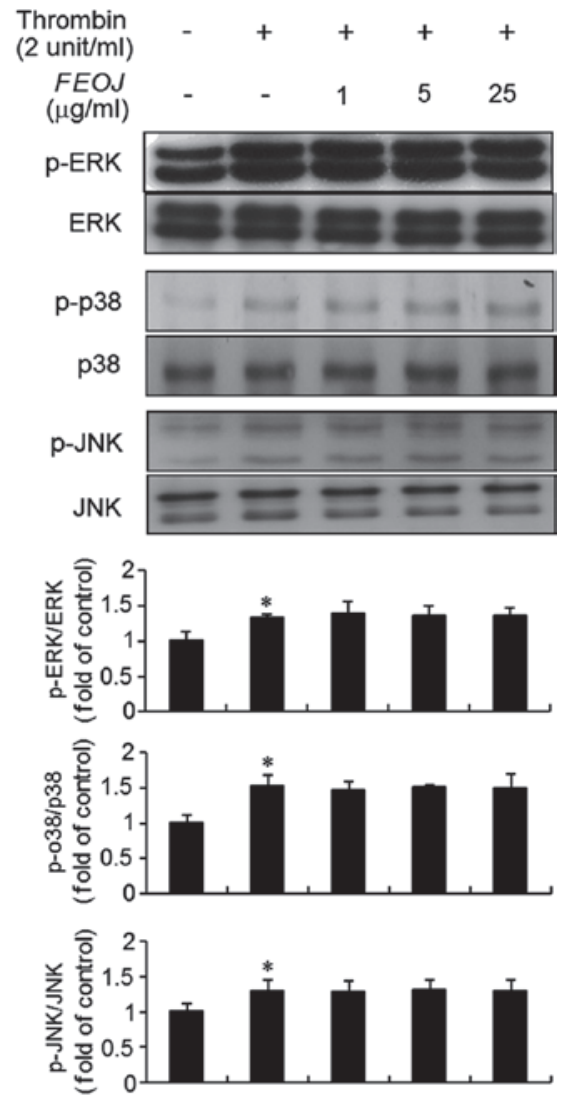

$\mathbf{B}$

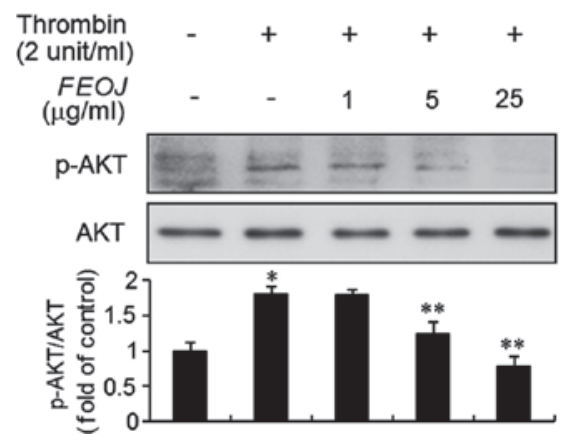

Figure 3. FEOJ inhibits the phosphorylation of AKT in thrombin-treated VSMCs. (A and B) VSMCs were pre-treated with various concentrations of FEOJ for $40 \mathrm{~min}$ and then stimulated with thrombin $(2 \mathrm{U} / \mathrm{ml})$ for $10 \mathrm{~min}$. Immunoblot analysis was performed using antibodies specific for $\mathrm{p}$-ERK1/2, ERK1/2, p-p38, p38, p-JNK, JNK, p-AKT and AKT. Values are expressed as the mean \pm standard error from three triplicate experiments. ${ }^{*} \mathrm{P}<0.01$ compared with no thrombin treatment. ${ }^{* *} \mathrm{P}<0.01$ compared with no thrombin treatment. p-ERK, phosphorylated extracellular signal-regulated kinase; JNK, c-Jun N-terminal kinase. FEOJ, extract of fermented Ophiopogon japonicas; VSMC, vascular smooth muscle cell.

adduct in the gel were transferred onto a nylon membrane and detected using horseradish peroxidase-conjugated streptavidin (cat. no. AY1000; Panomics) and a chemiluminescent substrate (Panomics). Gray value analysis of the blots was measured by ImagePro Plus 6.0 software (Media Cybernetics, Rockville, MD, USA)

Statistical analysis. All data are presented as the mean \pm standard error. Comparisons between two groups were analyzed with factorial analysis of variance and Fisher's least significant difference test. $\mathrm{P}<0.05$ was considered to indicate a statistically significant difference. Statistical analysis was performed using PASW Statistics 18.0.1 software (SPSS, Inc., Chicago, IL, USA).

\section{Results}

FEOJ inhibits thrombin-induced proliferation of VSMCs. To examine the effects of FEOJ on the viability of VSMCs, an MTT assay was used. Thrombin treatment for $24 \mathrm{~h}$ increased the cell viability by $\sim 1.8$-fold of that of non-treated control cells (Fig. 1A). However, thrombin-induced viability of VSSCs was suppressed by FEOJ $(1-25 \mu \mathrm{g} / \mathrm{ml})$ in a concentration-dependent manner (Fig. 1A). Furthermore, as shown in Fig. 1B, FEOJ suppressed the viability of VSMCs induced by thrombin in a time-dependent manner, while FEOJ alone $(1-25 \mu \mathrm{g} / \mathrm{ml})$ did not affect cell viability (Fig. 1A). These results indicated that FEOJ suppressed the proliferation of VSMCs induced by thrombin.

FEOJ suppresses positive cell-cycle regulator cyclin D1 and induces cell-cycle inhibitor p27KIP1 in thrombin-treated $V S M C s$. As FEOJ inhibited the proliferation of thrombin-treated VSMCs, the present study next examined the effects of FEOJ on G1-phase cell-cycle proteins using immunoblot analysis. As shown in Fig. 2A, thrombin treatment resulted in a significant increase of cyclin D1 expression in VSMCs. However, the expression of cyclin E, CDK2, and CDK4 in VSMCs was not affected by thrombin treatment (Fig. 2A). Of note, Pre-treatment of VSMCs with FEOJ inhibited the cyclin D1 expression (Fig. 2A). Previous studies demonstrated that CDKs and cyclins are negatively regulated by cyclin-dependent kinase inhibitors, including p21WAF1 and p27KIP1 $(15,16)$. Therefore, the present study examined the effects of FEOJ on p21WAF1 and p27KIP1 expression in thrombin-treated VSMCs. Treatment of VSMCs with thrombin induced the expression of p21WAF1, which was, however, not affected by FEOJ (Fig. 2B). By contrast, p27KIP1 expression was decreased by thrombin treatment in VSMCs, which was reversed by FEOJ (Fig. 2B). However, the expression of p53 in VSMCs was not affected by thrombin with or without FEOJ pre-treatment (Fig. 2B). These results indicated that FEOJ-induced inhibition of cell proliferation was mediated via reduction of thrombin-induced expression of the G1-phase cell-cycle protein cyclin D1 and reversal of thrombin-induced inhibition of the expression of cell cycle inhibitor p27KIP1 in VSMCs.

FEOJ inhibits thrombin-induced phosphorylation of AKT in VSMCS. Previous studies have demonstrated that thrombin stimulates the phosphorylation of ERK1/2, JNK, p38/MAPK and AKT in VSMCs (2). Therefore, the present study examined the effects of FEOJ on the intracellular signaling pathway induced by thrombin in VSMCs. As expected, after stimulation with thrombin for $10 \mathrm{~min}$, the expression levels of ERK1/2, JNK, p38/MAPK and AKT in VSMCs were significantly increased (Fig. 3A and B). Of note, pre-treatment of the cells with FEOJ inhibited AKT phosphorylation induced by thrombin (Fig. 3B). However, thrombin-induced phosphorylation of ERK1/2, JNK and p38MAPK was not affected by FEOJ (Fig. 3A). These results suggested that FEOJ blocks 

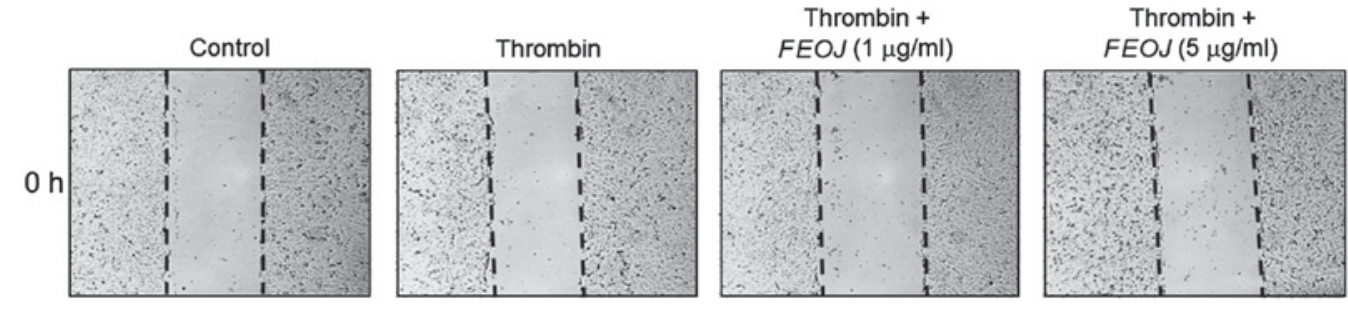

Thrombin + FEOJ $(25 \mu \mathrm{g} / \mathrm{ml})$
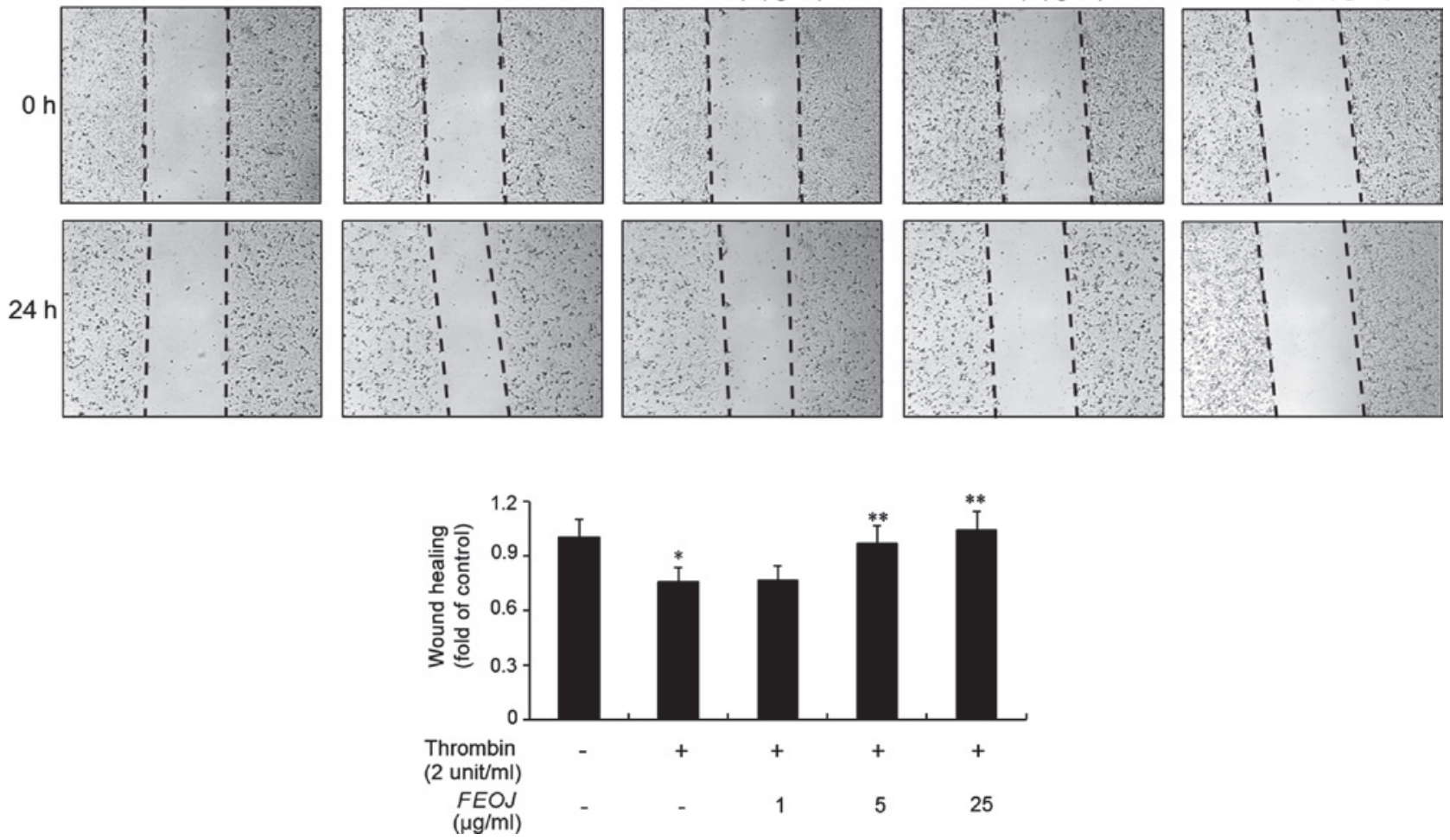

Figure 4. FEOJ inhibits the migration of vascular smooth muscle cells induced by thrombin. Serum-starved cells were cultured with indicated concentrations of FEOJ for $40 \mathrm{~min}$. Cells were then scratched and treated with thrombin $(2 \mathrm{U} / \mathrm{ml})$ for $24 \mathrm{~h}$. Images of wound closure were captured and analyzed using an inverted microscope (magnification, $\mathrm{x} 40$ ). Values are expressed as the mean \pm standard error from three independent experiments. "P $<0.01$ compared with no thrombin treatment. ${ }^{* *} \mathrm{P}<0.01$ compared with no thrombin treatment. FEOJ, extract of fermented Ophiopogon japonicas.

A

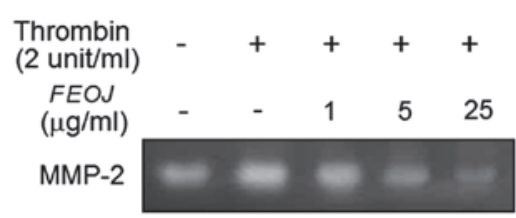

B
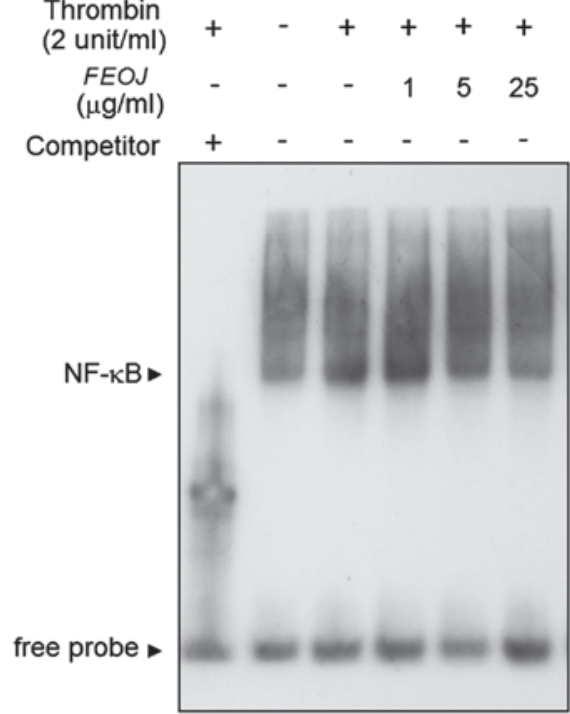
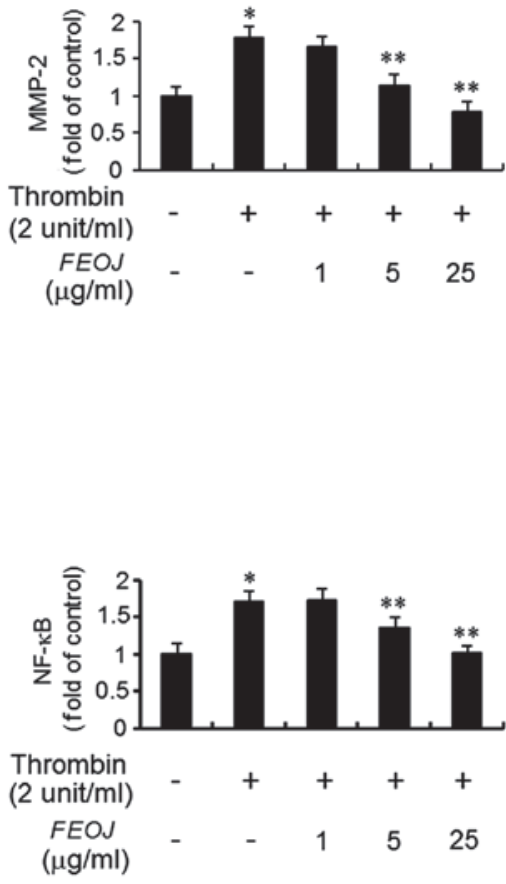

Figure 5. FEOJ suppresses the expression of MMP-2 and the decreased binding activity of the NF-kB motif in thrombin-treated VSMCs. Quiescent VSMCs were incubated on FEOJ for 40 min and then stimulated with thrombin ( 2 units $/ \mathrm{ml}$ ) for $24 \mathrm{~h}$. (A) The culture supernatants were examined zymographically for MMP-2 activity. (B) The activated NF- $\mathrm{KB}$ from the nuclear extract was evaluated by electrophoretic mobility shift assay using a biotin-labeled probe. Values are expressed as the mean \pm standard error from three independent experiments. ${ }^{*} \mathrm{P}<0.01$ compared with no thrombin treatment. ${ }^{* *} \mathrm{P}<0.01$ compared with no thrombin treatment. FEOJ, extract of fermented Ophiopogon japonicas; VSMC, vascular smooth muscle cell; MMP, matrix metalloproteinase; NF, nuclear factor. 
thrombin-induced proliferation of VSMCs via suppressing the AKT signaling pathway.

FEOJblocks thrombin-inducedmigration of VSMCs. Migration of VSMCs is a main step in atherosclerosis $(1,2)$ and thrombin has been reported to induce migration of VSMCs $(4,5)$. To investigate whether FEOJ inhibits thrombin-induced migration of VSMCs, a wound-healing assay was used. As shown in Fig. 4, treatment of VSMCs with thrombin for $24 \mathrm{~h}$ caused a significant increase in cell migration. However, pre-treatment with FEOJ inhibited thrombin-induced VSMC migration in a concentration-dependent manner (Fig. 4). These results suggested that FEOJ suppresses thrombin-stimulated migration of VSMCs.

FEOJ abolishes thrombin-stimulated MMP-2 expression via the inhibition of $N F-\kappa B$ binding activity. Accumulating evidence suggested that MMP-2 expression is involved in the migration of VSMCs $(4,5)$. To investigate the efficacy of FEOJ in blocking the regulation of MMP-2 expression by thrombin, a gelatin zymographic assay was employed. Treatment of VSMCs with thrombin resulted in a significant increase of MMP-2 expression, which was suppressed by FEOJ (Fig. 5A). To elucidate the underlying regulatory mechanism of the inhibitory effects of FEOJ on thrombin-induced MMP-2 expression, an EMSA assay was used. The results revealed that nuclear extracts of VSMCs treated with thrombin strongly stimulated the DNA-binding activity of NF- $\kappa \mathrm{B}$ (Fig. 5B). However, FEOJ treatment abrogated the increased $N F-\kappa B$ binding activity in thrombin-treated VSMCs (Fig. 5B). These results demonstrated that FEOJ abolished thrombin-induced MMP-2 expression, at least in part, by inhibiting the DNA-binding

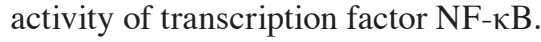

\section{Discussion}

Fermented medicinal herbs have been demonstrated to be suitable for treating a wide range of diseases, including cerebral hemodynamics, esophageal cancer, locally prevalent inflammatory reactions, scapulohumeral periarthritis (of the stasis type), chronic superficial gastritis and dysuria (13). The present study investigated the mechanisms of the anti-atherogenic effects of FEOJ on VSMCs stimulated by thrombin.

The present study showed that FEOJ treatment inhibited thrombin-induced proliferation of VSMCs without exerting any cytotoxic effects, as evidenced by an MTT assay. The suppressive effects of FEOJ were associated with the inhibition of G1-phase cell-cycle regulatory protein cyclin D1. The results of the present study demonstrated that FEOJ treatment significantly attenuated thrombin-induced increases in the expression of cyclin D1 in VSMCs. The expression of cyclins and CDKs is highly regulated by the cyclin-dependent kinase inhibitors p21WAF1 and p27KIP1 $(15,16)$. It has been demonstrated that $\mathrm{p} 27 \mathrm{KIP} 1$ expression was reduced during vascular injury (17). In addition, adenovirus-mediated overexpression of p27 suppressed neointimal lesion formation in balloon-injured arteries (18). The present study reported a distinct downregulation of p27KIP1 expression in VSMCs treated with thrombin, which was reversed by pre-treatment with FEOJ. p21WAF1 was originally identified as an anti-proliferative factor $(16,17)$.
Several lines of evidence showed that p21WAF1 expression is involved in the proliferation and migration of VSMCs $(19,20)$. In the present study, thrombin stimulated p21WAF1 expression, which was not affected by pre-treatment with FEOJ. These results demonstrated that inhibition of cell growth by FEOJ is due to attenuation of thrombin-induced increases of G1-phase cell-cycle regulatory protein cyclin D1 through reversal of thrombin-induced reduction of p27KIP1.

Mitogenic stimuli mediate signaling through various pathways in VSMCs, including the MAPK and AKT pathways $(2,3,5,20,21)$. The present study therefore investigated the effects of FEOJ on the early MAPK and AKT signal transduction pathways induced by thrombin in VSMCs. In previous studies, treatment of VSMCs with thrombin stimulated the phosphorylation of AKT and MAPKs, including ERK1/2, JNK and p38MAPK $(2,3)$. Furthermore, in agreement with the cell proliferation data, FEOJ treatment significantly inhibited the phosphorylation of AKT in thrombin-treated VSMCs. However, FEOJ treatment had no effect on the phosphorylation of MAPKs, including ERK1/2, JNK and p38MAPK in VSMCs treated with thrombin. These results suggested that FEOJ suppressed thrombin-induced proliferation of VSMCs via inhibiting AKT phosphorylation. Previous studies have suggested that the phosphorylation of AKT was decreased following OJ treatment in lung cancer cells and diabetic KKAy mouse model $(22,23)$, while the present study was the first to demonstrate that AKT phosphorylation is implicated in FEOJ-induced inhibition of VSMCs proliferation.

The migration of VSMCs is one of the crucial processes in the formation of atherosclerotic lesions $(4,5)$. Degradation of the extracellular matrix by enzymes including MMP-2 is an essential process in the migration of VSMCs, subsequently leading to the progression of arterial vascular neointimal lesions $(4,5)$. In the present study, the thrombin-induced migratory capacity of VSMCs was reduced by pre-treatment with FEOJ. In addition, the present study demonstrated that FEOJ suppressed the expression of MMP-2 in thrombin-stimulated VSMCs. Several lines of evidence have demonstrated that transcription factor $\mathrm{NF}-\kappa \mathrm{B}$ has pivotal roles in OJ-mediated protection of cerebral ischemic injury and anti-inflammatory activity $(7,24)$. Based on these previous studies, an EMSA assay was performed to gain further insight into the inhibitory regulation of MMP-2 expression by FEOJ in thrombin-induced VSMCs. The present study showed that FEOJ treatment resulted in a significant downregulation of the $\mathrm{NF}-\kappa \mathrm{B}$ DNA-binding activity in thrombin-treated VSMCs. These results suggested that FEOJ treatment leads to the downregulation of thrombin-induced MMP-2 expression via the suppression of $\mathrm{NF}-\kappa \mathrm{B}$ binding activity in VSMCs, resulting in a halt in extracellular matrix destruction and the prevention of cell migration.

In conclusion, the present study was the first to suggest that FEOJ suppressed the proliferation of thrombin-induced VSMCs via a reduction of AKT phosphorylation, while not showing any cytotoxicity. In addition, FEOJ-induced inhibition of VSMC proliferation was due to inhibition of thrombin-induced upregulation of cyclin D1 through reversal of thrombin-induced reduction of p27KIP1 expression. Furthermore, pre-treatment with FEOJ impeded thrombin-stimulated migration of VSMCs. In addition, FEOJ potently suppressed thrombin-stimulated expression of MMP-2 through downregulating NF- $\kappa \mathrm{B}$ binding 
activity. These results indicated that FEOJ may be able to prevent cardiovascular diseases associated with the proliferation and migration of VSMCs. Further study is required to investigate the efficacy of the FEOJ in vivo by determining its potential inhibitory effects on the formation of atherosclerotic lesions.

\section{Acknowledgements}

The present study was supported by the 'Food Functionality Evaluation Program' under the Ministry of Agriculture, Food and Rural Affairs and in part by the Korea Food Research Institute (grant no. 20140114). This research was supported by the Chung-Ang University Research Scholarship Grants in 2014.

\section{References}

1. Siller-Matula JM, Schwameis M, Blann A, Mannhalter C and Jilma B: Thrombin as a multi-functional enzyme. Focus on in vitro and in vivo effects. Thromb Haemost 106: 1020-1033, 2011.

2. Patterson C, Stouffer GA, Madamanchi N and Runge MS: New tricks for old dogs: Nonthrombotic effects of thrombin in vessel wall biology. Circ Res 88: 987-997, 2001.

3. Moon SK, Thompson LJ, Madamanchi N, Ballinger S, Papaconstantinou J, Horaist C, Runge MS and Patterson C: Aging, oxidative responses and proliferative capacity in cultured mouse aortic smooth muscle cells. Am J Physiol Heart Circ Physiol 280: H2779-H2788, 2001.

4. Galis ZS, Kranzhöfer R, Fenton JW II and Libby P: Thrombin promotes activation of matrix metalloproteinase- 2 produced by cultured vascular smooth muscle cells. Arterioscler Thromb Vasc Biol 17: 483-489, 1997.

5. Smiljanic K, Obradovic M,Jovanovic A,Djordjevic J,Dobutovic B, Jevremovic D, Marche P and Isenovic ER: Thrombin stimulates VSMC proliferation through an EGFR-dependent pathway: Involvement of MMP-2. Mol Cell Biochem 396: 147-160, 2014.

6. Chen HT, Tsou HK, Tsai CH, Kuo CC, Chiang YK, Chang CH, Fong YC and Tang $\mathrm{CH}$ : Thrombin enhanced migration and MMPs expression of human chondrosarcoma cells involves PAR receptor signaling pathway. J Cell Physiol 223: 737-745, 2010.

7. Huang YL, Kou JP, Ma L, Song JX and Yu BY: Possible mechanism of the anti-inflammatory activity of ruscogenin: Role of intercellular adhesion molecule-1 and nuclear factor-kappaB. J Pharmacol Sci 108: 198-205, 2008.

8. Kou J, Sun Y, Lin Y, Cheng Z, Zheng W, Yu B and Xu Q: Anti-inflammatory activities of aqueous extract from Radix Ophiopogon japonicus and its two constituents. Biol Pharm Bull 28: 1234-1238, 2005.

9. Kou J, Yu B and Xu Q: Inhibitory effects of ethanol extract from Radix Ophiopogon japonicus on venous thrombosis linked with its endothelium-protective and anti-adhesive activities. Vascul Pharmacol 43: 157-163, 2005.
10. Qian J, Jiang F, Wang B, Yu Y, Zhang X, Yin Z and Liu C: Ophiopogonin D prevents $\mathrm{H} 2 \mathrm{O} 2$-induced injury in primary human umbilical vein endothelial cells. J Ethnopharmacol 128: 438-445, 2010

11. Kou J, Tian Y, Tang Y, Yan J and Yu B: Antithrombotic activities of aqueous extract from Radix Ophiopogon japonicus and its two constituents. Biol Pharm Bull 29: 1267-1270, 2006.

12. Yan L and Kim IH: Effect of dietary grape pomace fermented by Saccharomyces boulardii on the growth performance, nutrient digestibility and meat quality in finishing pigs. Asian Austral J Anim 24: 1763-1770, 2011.

13. Choi YK, Sul JU, Park SK, Yu SN, Kim SH, Rhee MS, Ahn SC and Shin MS: Research trends of fermented medicinal herbs-based on their clinical efficacy and safety assessment. J Life Science 22: 1729-1739, 2012.

14. Moon SK, Cha BY and Kim CH: ERK1/2 mediates TNF-alpha-induced matrix metalloproteinase-9 expression in human vascular smooth muscle cells via the regulation of NF-kappaB and AP-1: Involvement of the ras dependent pathway. J Cell Physiol 198: 417-427, 2004.

15. Xiong Y, Hannon GJ, Zhang H, Casso D, Kobayashi R and Beach D: P21 is a universal inhibitor of cyclin kinases. Nature 366: 701-704, 1993.

16. Toyoshima $\mathrm{H}$ and Hunter T: P27, a novel inhibitor of G1 cyclin-Cdk protein kinase activity, is related to p21. Cell 78: 67-74, 1994.

17. Tanner FC, Yang ZY, Duckers E, Gordon D, Nabel GJ and Nabel EG: Expression of cyclin-dependent kinase inhibitors in vascular disease. Circ Res 82: 396-403, 1998

18. Chen D, Krasinski K, Sylvester A, Chen J, Nisen PD and Andrés V: Downregulation of cyclin-dependent kinase 2 activity and cyclin A promoter activity in vascular smooth muscle cells by p27 (KIP1), an inhibitor of neointima formation in the rat carotid artery. J Clin Invest 99: 2334-2341, 1997.

19. Besson A, Dowdy SF and Roberts JM: CDK inhibitors: Cell cycle regulators and beyond. Dev Cell 14: 159-169, 2008.

20. Moon SK, Kim HM, Lee YC and Kim CH: Disialoganglioside (GD3) synthase gene expression suppresses vascular smooth muscle cell responses via the inhibition of ERK1/2 phosphorylation, cell cycle progression and matrix metalloproteinase-9 expression. J Biol Chem 279: 33063-33070, 2004.

21. Zhan Y, Kim S, Izumi Y, Izumiya Y, Nakao T, Miyazaki H and Iwao H: Role of JNK, p38 and ERK in platelet-derived growth factor-induced vascular proliferation, migration and gene expression. Arterioscler Thromb Vasc Biol 23: 795-801, 2003.

22. Chen M, Du Y, Qui M, Wang M, Chen K, Huang Z, Jiang M, Xiong F, Chen J, Zhou J, et al: Ophiopogonin B-induced autophagy in non-small cell lung cancer cells via inhibition of the PI3K/Akt signaling pathway. Oncol Rep 29: 430-436, 2013.

23. Wang LY, Wang Y, Xu DS, Ruan KF, Feng Y and Wang S: MDG-1, a polysaccharide from Ophiopogon japonicus exerts hypoglycemic effects through the PI3K/Akt pathway in a diabetic KKAy mouse model. J Ethnopharmacol 143: 347-354, 2012.

24. Guan T, Liu Q, Qian Y, Yang H, Kong J, Kou J and Yu B: Ruscogenin reduces cerebral ischemic injury via $\mathrm{NF}-\kappa \mathrm{B}$-mediated inflammatory pathway in the mouse model of experimental stroke. Eur J Pharmacol 714: 303-311, 2013. 